\title{
THE RELATIONSHIP BETWEEN SOCIOECONOMIC STATUS AND KNOWLEDGE ON CARDIOVASCULAR RISK FACTORS AND ITS PREVENTIVE PRACTICES AMONG URBAN DWELLERS IN SELANGOR, MALAYSIA
}

\author{
Siti Munira Yasin ${ }^{1,2^{*}}$, Mohamad Rodi Isa ${ }^{1}$, Nurhuda Ismail ${ }^{1,2}$, Leny Suzana Suddin ${ }^{1}$, Mohammad Shahril \\ Ahmad Saman ${ }^{1}$ and Zaliha Ismail ${ }^{1}$ \\ ${ }^{1}$ Department of Public Health Medicine, Faculty of Medicine, Universiti Teknologi MARA, 47000,Sungai Buloh, \\ Selangor Malaysia. \\ ${ }^{2}$ Center for Occupational Safety, Health and Wellbeing, UiTM Selangor, Malaysia \\ *Corresponding author: Siti Munira Yasin \\ Email: sitimu.yasin@gmail.com
}

\begin{abstract}
To assess knowledge, practices on cardiovascular disease (CVD) prevention and practices among an urban population in Selangor. A cross-sectional household survey was conducted involving 336 adults in 161 houses randomly selected from three towns in Selangor, Malaysia. The mean knowledge of cardiovascular risk factors was moderately high among participants. Socioeconomic characteristics (SES) significantly associated with higher mean scores were being in middle age, female, high-income group and never smokers. Although the general knowledge on preventing cardiovascular risks among the urban population was moderately high, their lifestyle practices on preventing cardiovascular disease were moderate.
\end{abstract}

Keywords: Cardiovascular risk; prevention; urban

\section{INTRODUCTION}

CVDs, according to WHO is the number one cause of death globally ${ }^{1}$. Most cardiovascular diseases can be prevented by addressing the associated risk factors such as unhealthy diet, smoking, obesity and physical inactivity ${ }^{1}$. The risk factors associated with cardiovascular diseases are demonstrated by an increase in blood glucose, blood pressure and blood lipids. Sometimes it is shown as the individual being overweight and obese $^{2}$. Fortunately, this problem can be easily assessed and can be prevented. It can also be avoided early if screening was to be done ${ }^{3}$.

In Malaysia, the risk factors for CVS had shown an increasing trend. The National Health and Morbidity Survey in 2011 reported that about $32.7 \%$ of the population were found to be hypertensive, with two-thirds of them being newly diagnosed cases. Meanwhile, $15.2 \%$ of the population had diabetes, with more than half of the newly diagnosed cases. In addition, 35.1\% were affected by hypercholesterolemia (serum total cholesterol $>5.2 \mathrm{mmol} / \mathrm{L})^{4}$. In the recent National Health and Morbidity Survey 2015, there was an increase in diabetes prevalence to $17.5 \%$, with a slight reduction in the prevalence of hypertension to $30.3 \%$ and reduced in newly diagnosed cases. Nonetheless, there was an alarming increase of hypercholesterolemia's prevalence to $47.7 \%$, from the previous $35.1 \%$ in $2011^{5}$.
Knowledge about CVD and its risk factors is essential to change the individuals' health attitudes, behaviours and lifestyle practices ${ }^{6,7}$. Knowledge of the preventive aspects of CVD is as crucial, as this may enhance an individual's motivation for that change in behaviour and improvement in patient outcome ${ }^{8}$. Good knowledge on CVD risk factors among individuals will help them be proactive in decreasing their risk since most of the risk factors are modifiable ${ }^{2}$. While previous studies looked into knowledge of CVS, only one previous study looked into the knowledge of prevention of CVS and its preventive practices ${ }^{9}$.

Factors that influence CVD risk are various and include socioeconomic statuses (SES), such as education, marital status, living status, income, and employment status ${ }^{10}$. It was reported previously that individuals with low SES were more likely to engage in unhealthy behaviours ${ }^{11}$, hence, it is a likelihood of having cardiovascular risk factors ${ }^{12}$. The most recent study revealed that individuals with short education status and low socioeconomic status were more likely to have lesser knowledge on CVS risk factors ${ }^{9}$. In Malaysia and Southeast Asia, no such study thus far had delved into this issue.

The main aim of this study is to assess the knowledge of CVS prevention and its related practices. Secondly, investigate the relationship between SES and knowledge on CVS risk factors and prevention practices among these urban dwellers. To the best of our knowledge, the 
relationship between SES and knowledge on cardiovascular risk factors and its preventive practices has not yet been examined.

\section{METHODOLOGY}

A cross-sectional study was conducted between December 2017 and February 2018. The targeted respondents for this study were populations from three residential areas in Shah Alam, Selangor. The residential areas were randomly selected from the entire Shah Alam city. Subsequently, a systematic sampling method was applied to obtain the respondents. Every third house from the first house (the total houses in the 3 residential areas are 600 houses with participation of at least 2 members from each house).

A total population sampling method was done to collect respondents from each house. An interview was conducted to all members of the household who were eligible to participate. Inclusion criteria included adults, able to read, write, communicate, and understand Bahasa Malaysia or English and provide consent to participate. Those below 18 years old were excluded from the study.

Data collection was implemented by a selfadministered method using a set of validated and structured questionnaires. The interviewers were trained before the administration of the questionnaire. The questionnaire comprised three parts. Part A was the sociodemographic data and previous medical history. This consisted of age, gender, race, religion, occupation, the highest level of education, marital status, total household income, smoking status, body mass index (BMI), abdominal obesity, the intensity of physical activity and any underlying diseases (Diabetes, Hypertension and Hypercholesterolemia).

Age was categorized as young adults (18-35 years old), middle-aged adults (36-55 years old) and older adults ( $>55$ years old). Smoking status was categorized as never (does not smoked at all), current smoker (an adult who has smoke 100 cigarettes in his/her lifetime and who currently smokes cigarettes) and former smoker (never smoke daily for six months or more). Underlying diseases were marked either as yes or no.

Part $B$ discussed on Knowledge on cardiovascular risk factors. This comprised of 25 statements, which were adapted from a validated local questionnaire ${ }^{13}$. Answer choices of True and False were given. The correct answer was labelled as 1 and the incorrect answer labelled as 0 . Total marks were calculated as percentage marks and analysed as continuous data.

Practice on preventing cardiovascular risk factors was assessed in Part $C$ which consists of 10 statements. Questions 1 to 6 was assessed by Likert scale 'Never', 'Seldom', 'Frequently' and 'Always' and labelled as 1,2,3 and 4 respectively.
However, we used reverse scoring for question 7 to 10 and it was marked as 4, 3, 2 and 1 respectively. This questionnaire has also been validated locally in Malay version and English version in a previous study ${ }^{14}$.

The Sample size calculation was done by using Open Epi software. The expected frequency was $63.4 \%$, which was based on a previous study ${ }^{15}$, taking into account $95 \%$ confidence interval, alpha 0.05 and $80 \%$ power. After considering $20 \%$ of the non-response rate, the final estimated sample size was 396 individuals.

Data entry and analysis were done by using SPSS version 22.0. All data were displayed as numbers, percentages, mean, median, mode, standard deviation, mean differences, $\mathrm{p}$-value and $95 \%$ confidence interval. Categorical data was displayed by absolute number and frequency. Continuous data was interpreted by the mean and standard deviation. Bivariate analysis was used to examine the relationships between independent and dependent variables. Independent T-test was used to study the mean difference of score of knowledge of cardiovascular disease and score of practice on preventing cardiovascular disease between groups of 5 different sources of health seeking behaviour.

We used ANOVA to compare mean difference of score of knowledge on cardiovascular risk factor and score of practice on preventing cardiovascular disease between groups in each category of sociodemographic and post hoc test Bonferroni to identify the significant pairs. Correlation and regression were used to study the correlation between the score of knowledge of cardiovascular disease and score of practice on preventing cardiovascular risk factors.

An approval to conduct this study was obtained from the Medical Research Ethics, Faculty of Medicine, Universiti Teknologi Mara (UiTM) and UiTM Research Ethics. Written informed consent was elicited from the respondents prior to data collection to indicate their willingness to participate.

\section{RESULTS}

A total of 161 houses participated in our study with non- response rate was $34 \%$ from a total of 244 homes approached. The mean age of participants was $36.2( \pm 15.1)$. Meanwhile, the majority were female, Malay and Muslim with a percentage of $53.9 \%, 85.1 \%$ and $86.6 \%$, respectively. The majority of participants were non-smokers and approximately $59.8 \%$ had normal body mass index. Otherwise, for underlying chronic illnesses, i.e. diabetes, hypertension and hypercholesterolemia, the percentages were low among the respondents, which were 9.2\%, $15.2 \%$ and $15.2 \%$ respectively. 
Table 1 displays the knowledge on cardiovascular risk factors with Mean (SD): $78.96( \pm 13.71)$, Mode $=88 \%$, Median $=80 \%$. The question with the highest correct score was question no 8; 'high cholesterol is a risk factor for developing heart disease' with 93.2\%. There were two questions that majority of participants answered incorrectly which were 'only exercising at a gym in an exercise class will help lower a person's chance of developing heart disease' (67.6\%) and the question on 'people with diabetes tends to have low HDL (good) cholesterol' with percentage of and $(50.9 \%)$.

The mean score of practice on preventing cardiovascular risk factors was $64.94( \pm 8.97)$. The highest score of practice on preventing cardiovascular risk factor was $60 \%$, with a median score of $65 \%$. Overall, most of the participants seldom exercise and seldom practice a healthy diet. Most also claimed that they rarely lead a stressful life.

Results on the relationship between SES and knowledge on CVS found that there was some significant association with at least one pair of differences in mean of knowledge for age, gender, religion, income and smoking status among respondents. The middle-aged had higher scores compared to young adults; Mean difference of 4.386 with $95 \% \mathrm{Cl}[-8.33$ to -0.44$]$, for gender, the female has higher knowledge compared to male than male. In addition, in terms of religion, the mean of knowledge is statistically higher between people practicing Buddhism and people practicing Hinduism (15.06[95\% Cl (2.01 to 28.12)] and practicing Islam (12.80 [95\% $\mathrm{Cl}(2.36$ to 23.25$])$. As for income, there is a significant mean difference of knowledge between high income group and low income group $(8.33[95 \% \mathrm{Cl}$ (3.20-13.46)]. Moreover, people who never smoked cigarettes have a higher knowledge of smoking status compared to current smokers. [Mean difference of $5.29[95 \% \mathrm{Cl}(0.47-10.11)]$.

Table 2 indicates that there is at least one pair of differences in mean of knowledge for age, race, marital status, BMI, and physical activity. Post hoc tests revealed middle-aged has a higher score in mean practice in CVS prevention as compared to younger aged (mean difference of -3.564 with 95\% $\mathrm{CI}[-6.11-1.02])$ and elderly (mean difference of 5.064 with $95 \% \mathrm{Cl}[-8.61,-1.52])$, Malays have a higher score than other races $(p$-value $=0.003$, mean difference of -9.44 with $95 \% \mathrm{Cl}$ [$19.13,0.24])$, unmarried individuals have higher practice than those who are married (mean difference of -4.45 with $95 \% \mathrm{Cl}[-7.02-1.89]$ ), normal and overweight have higher mean scores than being single (mean difference of -4.01 with $95 \% \mathrm{Cl}[-7.02,-1.01])$. There are also higher mean scores for preventive practices in strenuous and moderate as compared to mild exercises (mean difference of $-4.06 ; 95 \% \mathrm{Cl}[-7.12-0.10]$; (mean difference of $-6.50 ; 95 \% \mathrm{Cl}[-10.85$ to -2.15$]$ respectively.

Based on table 3 , there is a significant weak positive correlation between factors affecting health-seeking behaviour and mean score of practice on preventing cardiovascular risk factors $(p=0.002, r=0.17)$.

\section{DISCUSSION}

This study aimed to determine the knowledge and practice on preventing cardiovascular disease risk factors and its association with socio-demographic characteristics. The mean score of knowledge obtained by the participants indicated an adequate to a high level of knowledge on cardiovascular risk factors. This is in line with studies looking into the knowledge of heart disease and cardiovascular problems ${ }^{16}$; however, knowledge of cardiovascular risk factors was unsatisfactory in studies conducted in the Western region17, 18. Most participants scored correctly on cholesterol being a risk factor for cardiovascular problems (over 90\% correct answers). We assume this could be due to massive promotion in various media regarding the danger of cholesterol. A majority of the participants answered two questions incorrectly. Firstly, related to the misconception that gym is the only method for exercising. The second question which people answered incorrectly was 'people with diabetes tend to have low HDL (good) cholesterol'. This means that participants were unaware of the different types of cholesterol and its effect on CVS. In addition, most possibly, they were unaware that there are cholesterols which may positively reduce CVS impacts.

Some aspects of SES tend to be associated with sufficient knowledge on cardiovascular risk factors. Our female respondents reported a higher mean score of knowledge than the male respondents, similar to a previous study ${ }^{19}$. We postulated that this might be due to the fact that the majority of our female respondents were housewives who usually have more time to seek health information from additional sources like the Internet, newspapers and other media. This correlates well with other studies ${ }^{13}$.Moreover, it was found that the higher the income status, the higher the knowledge on health a person has might be because individuals with better income are usually more educated, and could have greater access to various other sources of health information, a majority of which are in English language. We suspect these individuals also do not depend entirely on physician's advice for healthrelated issues, although further studies on this are needed. About smoking status, we also found that non-smokers have a higher mean score of knowledge as compared to smokers. This is expected, as earlier it was found that smokers tend to be more ignorant about their health, than non-smokers ${ }^{20}$. 
Table 1. Knowledge on cardiovascular risk factors

\begin{tabular}{|c|c|c|}
\hline Items & $\begin{array}{l}\text { Correctly } \\
\text { Answered } \\
\text { N (\%) }\end{array}$ & $\begin{array}{c}\text { Incorrectly } \\
\text { Answered } \\
\text { N (\%) }\end{array}$ \\
\hline A person always knows when they have a heart disease & $199(59.2)$ & $137(40.8)$ \\
\hline $\begin{array}{l}\text { If you have a family history of heart disease you are at risk for developing } \\
\text { heart disease }\end{array}$ & $256(76.2)$ & $80(23.8)$ \\
\hline The older a person is, the greater their risk of developing heart disease & $261(77.7)$ & $75(22.3)$ \\
\hline Smoking is a risk factor for heart disease & 304 (90.5) & $32(9.5)$ \\
\hline A person who stops smoking will lower their risk of developing heart disease & 265 (78.9) & $71(21.1)$ \\
\hline High Blood Pressure is a risk factors for heart disease & $303(90.2)$ & $33(9.8)$ \\
\hline $\begin{array}{l}\text { Keeping Blood Pressure under control will reduce a person's risk for } \\
\text { developing heart disease }\end{array}$ & $308(91.7)$ & $28(8.3)$ \\
\hline High cholesterol is a risk factor for developing heart disease & $313(93.2)$ & $23(6.8)$ \\
\hline Eating fatty foods does not affect blood cholesterol level & $263(78.3)$ & 73 (21.7) \\
\hline If your 'good' cholesterol (HDL) is high you are at risk for I & $225(67.0)$ & $111(33.0)$ \\
\hline If your 'bad' choles & $299(89.0)$ & $37(11.0)$ \\
\hline Being overweight in & $308(91.7)$ & $28(8.3)$ \\
\hline $\begin{array}{l}\text { Regular physical activity will lower a person's chance of getting heart } \\
\text { disease }\end{array}$ & $302(89.9)$ & $34(10.1)$ \\
\hline $\begin{array}{l}\text { Only exercising at a gym in an exercise class will help lower a person's } \\
\text { chance of developing heart disease }\end{array}$ & $109(32.4)$ & 7.6) \\
\hline $\begin{array}{l}\text { Walking and gardening are considered exercise that will help lower a } \\
\text { person's chance of developing heart disease }\end{array}$ & $305(90.8)$ & $31(9.2)$ \\
\hline Diabetes is a risk factors for developing heart disease & $231(68.8)$ & $105(31.3)$ \\
\hline ut a strain on your heart & $282(83.9)$ & $54(16.1)$ \\
\hline $\begin{array}{l}\text { If your blood sugar is high over several months, it can cause your cholesterol } \\
\text { level to go up and increase your risk of heart disease }\end{array}$ & $287(85.4)$ & $49(14.6)$ \\
\hline $\begin{array}{l}\text { A person who has diabetes can reduce their risk of developing heart disease } \\
\text { if they keep their blood sugar levels under control }\end{array}$ & $240(71.4)$ & $96(28.6)$ \\
\hline People with diabetes rarely have high cholesterol & $250(74.4)$ & $86(25.6)$ \\
\hline $\begin{array}{l}\text { If a person has diabetes, keeping his cholesterol under control will help to } \\
\text { lower his chance of developing heart disease }\end{array}$ & $291(86.6)$ & $45(13.4)$ \\
\hline People with diabetes tends to have low HDL (good) cholesterol & $171(50.9)$ & $165(49.1)$ \\
\hline $\begin{array}{l}\text { A person who has diabetes can reduce their risk of developing heart disease } \\
\text { if they keep their blood pressure under control }\end{array}$ & $254(75.6)$ & $82(24.4)$ \\
\hline $\begin{array}{l}\text { A person who has diabetes can reduce their risk of developing heart disease } \\
\text { if they keep their weight under control }\end{array}$ & $264(78.6)$ & $72(21.4)$ \\
\hline $\begin{array}{l}\text { Men with diabetes have a higher risk of heart disease than women with } \\
\text { diabetes }\end{array}$ & $228(67.9)$ & $108(32.1)$ \\
\hline
\end{tabular}

There is also some positive relationship between SES and practices on the prevention of CVS. The younger adults scored poorly on methods of preventing cardiovascular risk factors compared to middle-aged adults and the elderly. This is in line with the theory that the volume of sedentary behaviour decreased with age and retired people (older adults) are more active because they choose to spend their time doing various activities to enhance their quality of life ${ }^{21}$. Secondly, results revealed that married respondents had better practice compared to single adults. An explanation might be because having young children at home, might increase fruits and vegetable intake at home and that the companionship provided by marriage may be associated with a healthier eating habit ${ }^{22}$. Our study also found that people with higher body mass have lower practice scores. This is expected as individuals are less health conscious as would presume to poorly adapt to a healthy lifestyle.

Theoretically, to practice a healthy lifestyle in preventing of cardiovascular disease development, one must have adequate and correct information on CVD risk factors. However, there is no significant association between knowledge and practice on CVD disease in the present study. This shows that knowledge does not necessarily lead to preventive behaviour (18, 23 ), and not inevitably translated into practice. Further research is required to find effective ways on how to translate knowledge into practice. 
Table 2. The relationship between SES and practices of CVS prevention

\begin{tabular}{|c|c|c|c|c|c|c|}
\hline Variable & & $\mathbf{N}$ & Mean (SD) & $F(d f)$ & $(95 \% \mathrm{Cl})$ & $\mathrm{p}$-value \\
\hline \multirow[t]{3}{*}{ Age } & Young adult & 182 & $63.11(8.94)$ & 9.123 & $(61.81,64.42)$ & $<0.001$ \\
\hline & Middle aged & 110 & $66.68(8.34)$ & $(2,333)$ & $(65.10,68.25)$ & \\
\hline & Elderly & 44 & $68.18(9.02)$ & & $(65.44,70.92)$ & \\
\hline \multirow[t]{4}{*}{ Race } & Malay & 286 & $64.39(8.827)$ & 4.160 & $(63.28,65.33)$ & 0.007 \\
\hline & Chinese & 16 & $68.59(8.707)$ & $(3,332)$ & $(63.95,73.23)$ & \\
\hline & Indian & 28 & $67.50(9.477)$ & & $(63.82,71.17)$ & \\
\hline & Others & 6 & $73.75(6.471)$ & & $(66.96,80.54$ & \\
\hline \multirow[t]{4}{*}{ Occupation } & Unemployed & 146 & $63.81(9.23)$ & 2.615 & $(62.30,65.32)$ & 0.051 \\
\hline & Full-time & 138 & 65.79(8.49) & $(3,332)$ & $(64.36,67.22)$ & \\
\hline & Part-time & 25 & $63.40(9.78)$ & & $(59.36,67.44)$ & \\
\hline & Retired & 27 & $68.14(8.33)$ & & $(64.85,71.44)$ & \\
\hline \multirow[t]{4}{*}{$\begin{array}{l}\text { Highest level of } \\
\text { education }\end{array}$} & $\begin{array}{l}\text { No formal } \\
\text { education }\end{array}$ & 3 & 68.14(8.33) & $\begin{array}{l}2.604 \\
(3,332)\end{array}$ & $(64.85,71.44)$ & 0.052 \\
\hline & Primary & 14 & $65.00(12.50)$ & & $(33.94,96.05)$ & \\
\hline & Secondary & 98 & $60.18(10.67)$ & & $(54.01,66.34)$ & \\
\hline & Tertiary & 221 & $66.58(9.21)$ & & $(64.73,68.42)$ & \\
\hline \multirow[t]{4}{*}{ Marital status } & Single & 145 & $65.55(8.92)$ & 8.476 & $(61.08,64.01)$ & $<0.001$ \\
\hline & Married & 182 & 67.01(8.40) & $(3,332)$ & $(65.78,68.23)$ & \\
\hline & Divorced & 4 & $56.25(11.99)$ & & $(37.17,75.32)$ & \\
\hline & Widow/ widower & 5 & $66.50(9.61)$ & & $(54.55,78.44)$ & \\
\hline \multirow[t]{3}{*}{ Smoking status } & Never & 258 & 65.33(9.28) & 2.39 & $(64.19,66.46)$ & 0.093 \\
\hline & Current smoker & 56 & 62.63(7.29) & $(2,333)$ & $(60.68,64.58)$ & \\
\hline & Former smoker & 22 & $66.36(8.41)$ & & $(62.60,70.12)$ & \\
\hline \multirow[t]{4}{*}{ BMI } & Underweight & 26 & $63.26(8.41)$ & 4.814 & $(59.86,66.67)$ & 0.003 \\
\hline & Normal & 201 & $64.00(9.18)$ & $(3,332)$ & $(62.72,65.28)$ & \\
\hline & Overweight & 87 & 68.01(7.84) & & $(66.34,69.68)$ & \\
\hline & Obese & 22 & $63.40(9.49)$ & & $(59.19,67.62)$ & \\
\hline \multirow[t]{4}{*}{ Physical activity } & Sedentary & 35 & $60.42(8.25)$ & 11.421 & $(57.59,63.26)$ & $<0.001$ \\
\hline & Mild exercise & 191 & $63.73(8.11)$ & $(3,332)$ & $(62.57,64.88)$ & \\
\hline & Moderate exercise & 78 & $67.78(8.08)$ & & $(65.96,69.61)$ & \\
\hline & $\begin{array}{l}\text { Strenuous } \\
\text { exercise }\end{array}$ & 32 & $70.23(12.15)$ & & $(65.85,74.61)$ & \\
\hline \multirow[t]{2}{*}{ Underlying Diabetes } & Yes & 31 & $62.66(9.058)$ & 2.227 & $(59.33,65.96)$ & 0.137 \\
\hline & No & 305 & $65.18(8.52)$ & $(1,334)$ & $(64.17,66.18)$ & \\
\hline
\end{tabular}

Table 3. Correlation between mean score of knowledge and mean score of practices on preventing cardiovascular risk factors

\begin{tabular}{lccc}
\hline Variable & Mean(SD) & r & P \\
\hline Score of knowledge & $78.96( \pm 13.71)$ & 0.049 & 0.368 \\
Score of practice & $64.95( \pm 8.97)$ & & \\
\hline
\end{tabular}

Our study's strength is that it is a populationbased study, comprising various categories of healthy individuals. So the results of our research can represent the population. We also used systematic random sampling which means that the study was not biased and the sample taken was well represented. There are a few limitations in this study. Since most of our respondents had no underlying diabetes mellitus, hypertension and hypercholesterolemia, it is most likely that we could not capture the group who had these underlying diseases which are the risk factors for cardiovascular disease. In addition, the sampling areas are mostly dominated by Malays, so the results might not represent all racial groups. As this study is a cross-sectional study, there is no causal relationship in knowledge and practices, and incidence of diseases in the population. A more prominent study prospectively look into this in the near future.

\section{CONCLUSIONS}

Although general knowledge of cardiovascular risk factors in this population is moderate to high, we still suggest the need for programs to improve knowledge regarding cardiovascular risk factors in this population, especially on the role of good cholesterol as a protective factor for cardiovascular disease. Gender, income status and smoking status were significantly associated with a mean score of knowledge. Health policymakers should consider these findings when preparing education programs to enhance awareness of risk factors and prevent cardiovascular disease. The current program may 
require revision to be more tailored to those with high-risk groups and low education status. As evaluation of such programmes is much needed to ensure optimisation of healthcare resources for prevention purposes. Further studies are needed to determine the causative factors behind the identified knowledge gaps, and newer interventions to patients to ensure their motivation in translating the knowledge into practice remains high. Moreover, lifestyle practice on preventing cardiovascular disease is moderate, so we suggest intensifying campaign on healthy lifestyles especially on physical activity among all age groups.

\section{ACKNOWLEDGEMENT}

We would like to convey our thanks to the participants in this study and our special gratitude to the UiTM Medical Students of Year 4, PHM Rotation 3, 2017/2018, who assisted in this study.

\section{REFERENCES}

1. Mendis S. Global progress in prevention of cardiovascular disease. Cardiovasc diagn Ther. 2017;7(Suppl 1):S32.

2. Uthman OA, Hartley L, Rees K, Taylor F, Ebrahim S, Clarke A. Multiple risk factor interventions for primary prevention of cardiovascular disease in low- and middleincome

countries. Cochrane Database Syst Rev. 2015(8):Cd011163.

3. Patnode CD, Evans CV, Senger CA, Redmond N, Lin JS. U.S. Preventive Services Task Force Evidence Syntheses, formerly Systematic Evidence Reviews. Behavioral Counseling to Promote a Healthful Diet and Physical Activity for Cardiovascular Disease Prevention in Adults Without Known Cardiovascular Disease Risk Factors: Updated Systematic Review for the US Preventive Services Task Force. Rockville (MD): Agency for Healthcare Research and Quality (US); 2017.

4. Teh C, Lim K, Chan Y, Lim K, Azahadi O, Akmar $\mathrm{AH}$, et al. The prevalence of physical activity and its associated factors among Malaysian adults: findings from the National Health and Morbidity Survey 2011. Public health. 2014;128(5):416-23.

5. Health Mo. NHMS. National Health Morbidity Survey 2015. In: Health Mo, editor. Institue for Public Health: Institute for Public Health.

6. Wasniowska A, Kopec G, Szafraniec K, Misiowiec W, Waligora M, Brozda M, et al. Assessment of knowledge on cardiovascular disease risk factors by postal survey in residents of Malopolska Voivodeship. Malopolska Cardiovascular PReventive Intervention Study (M-CAPRI). Ann Agric Environ Med. 2017;24(2):201-6.

7. Kulkayeva G, Harun-Or-Rashid M, Yoshida Y, Tulebayev K, Sakamoto J. Cardiovascular disease risk factors among rural Kazakh population. Nagoya J Med Sci. 2012;74(1-2):51-61.

8. Lopez EP, Rice C, Weddle DO, Rahill GJ. The relationship among cardiovascular risk factors, diet patterns, alcohol consumption, and ethnicity among women aged 50 years and older. J Am Diet Assoc. 2008;108(2):248-56.

9. Tsuji M, Arima H, Ohkubo T, Nakamura K, Takezaki T, Sakata K, et al. Socioeconomic Status and Knowledge of Cardiovascular Risk Factors: NIPPON DATA2010. 2018;28(Supplement_III):S46s52.

10. Greenland P, Knoll MD, Stamler J, Neaton JD, Dyer AR, Garside DB, et al. Major risk factors as antecedents of fatal and nonfatal coronary heart disease events. Jama. 2003;290(7):891-7.

11. Stringhini $S$, Carmeli $C$, Jokela $M$, Avendaño $M$, Muennig $P$, Guida $F$, et al. Socioeconomic status and the $25 \times 25$ risk factors as determinants of premature mortality: a multicohort study and metaanalysis of 1.7 million men and women. The Lancet. 2017;389(10075):1229-37.

12. Fukuda Y, Hiyoshi A. Associations of household expenditure and marital status with cardiovascular risk factors in Japanese adults: analysis of nationally representative surveys. J Epidemiol. 2013;23(1):21-7.

13. Akintunde AA, Akintunde TS, Opadijo OG. Knowledge of heart disease risk factors among workers in a Nigerian University: A call for concern. Nigerian medical journal: J Med Assoc. 2015;56(2):91.

14. Ibrahim MM, Rahman NAA, Rahman NIA, Haque M. Knowledge, Attitude and Practice of Malaysian Public University Students on Risk Factors for Cardiovascular Diseases. 2016.

15. Khongbuh B, Walia I, Kapoor S. Prevalence of diabetes and treatment seeking behaviour among adult population at village Dhanas, UT, Chandigarh. Midwifery. 2005;1(3). 
16. Muhamad R, Yahya $R$, Yusoff $H M$. Knowledge, attitude and practice on cardiovascular disease among women in North-Eastcoast Malaysia. International Journal of Collaborative Research on Internal Medicine \& Public Health. 2012;4(1).

17. Wartak SA, Friderici J, Lotfi A, Verma A, Kleppel R, Naglieri-Prescod D, et al. Patients' knowledge of risk and protective factors for cardiovascular disease. Am J Cardiol. 2011;107(10):1480-8.

18. Akintunde AA, Akintunde T, Opadijo OG. Knowledge of heart disease risk factors among workers in a Nigerian University: A call for concern. Niger Med J. 2015;56(2):91-5.

19. Pratt CA, Ha L, Levine S, Pratt CB. Stroke knowledge and barriers to stroke prevention among African Americans: implications for health communication. $J$ health Commun. 2003;8(4):369-81.

20. Awad A, Al-Nafisi H. Public knowledge of cardiovascular disease and its risk factors in Kuwait: a cross-sectional survey. BMC public health. 2014;14(1):1131.

21. Godfrey A, Lord S, Galna B, Mathers JC, Burn DJ, Rochester L. The association between retirement and age on physical activity in older adults. Age and ageing. 2013;43(3):386-93.

22. Murray EK. Development and Testing of Measures to Assess Nutrition Behavior Change in Low Income Adults Participating in the Expanded Food and Nutrition Education Program: Colorado State University; 2017.

23. H M-G, T M, SL S, L M. Knowledge, preventive action, and barriers to cardiovascular disease prevention by race and ethnicity in women: an American Heart Association national survey. J Womens Health. 2010;19(7):1243-9. 